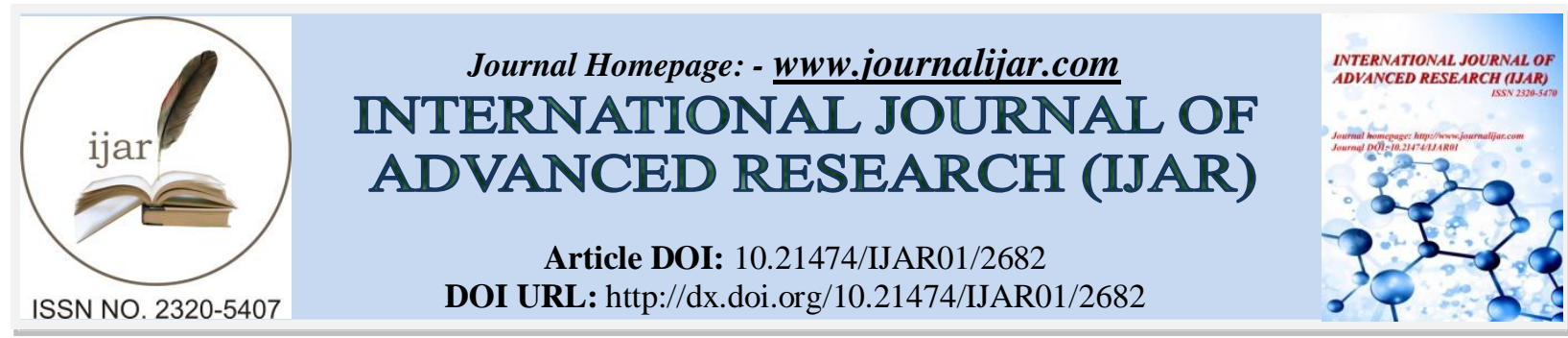

RESEARCH ARTICLE

\title{
FREQUENCY RATE OF ORAL CANDIDIASIS AMONG PATIENTS ON ONCOLOGY MANAGEMENT AT KHARTOUM ISOTOPE AND RADIATION TEACHING HOSPITAL.
}

Nagla M.A. Mohammed ${ }^{1}$, El Fadil E. Omer ${ }^{1}$ and El-Nour EL-Amin A. ${ }^{2}$.

1. Department of Medical Microbiology, Faculty of Medical Laboratory Sciences, Al-Neelain University

2. Department of Microbiology and Molecular biology- Faculty of Sciences and Technology- Al-Neelain University.

\section{Manuscript Info}

\section{Manuscript History}

Received: 31 October 2016

Final Accepted: 01 December 2016

Published: December 2016

Key words:-

Cancer patients, Candida species,

Chemotherapy, Radiotherapy.

\section{Abstract}

Background: Oropharyngeal candidiasis is one of the common manifestations seen in cancer patients on cytotoxic therapy and invasion into deeper tissues can occur if not treated promptly and little is known about the epidemiology of oral Candida colonization and infection in immunocompromised patients in developing countries. Thus this study was carried out to determine the frequency rate of oral candidiasis among patients on oncology management at Khartoum Isotope and Radiation Center.

Method: A total of 168 cancer patients under treatment of chemotherapy and /or radiotherapy were taken as 100 out-patients and 68 inpatients control group. Those were examined for oral candidiasis. For all patients, the clinical diagnosis had to be confirmed microbiologically by the presence of yeasts and / or hyphae or pseudohyphae on potassium hydroxide - treated smears of oral swabs. Oral samples were obtained and cultured on Sabouraud's dextrose agar.

Result: Out of 69 Candida isolates, total colonization was prevalent in $46(66.7 \%)$ and oral candidiasis in $23(33.3 .3 \%)$ of all cancer patients, representing $3(8.8 \%)$ and $20(57.1 \%)$ infection among outpatients and in-patients respectively.

Candida albicans was significantly more common than nan - candida albicans in both study group (76.5\% vs $32.5 \%)$ and control group (68.5\% vs. $31.4 \%)$.

Amongst the cancer group, $147(87.5 \%)$ had solid organ malignancy, $21(12.5 \%)$ had hematological malignancy.

High frequency of Candida isolates were detected among females, breast cancer, with chemotherapy treatment, among those who were from North Sudan and South Dar-for and among patients who belong to Al-gaalia tribe.

Conclusion: Oral candidiasis is more common among cancer patients with considerable risk to hospitalized patients.

Though Candida albicans was found as the most common species but non-albicans candida species are appearing as emerging pathogens as well.

Copy Right, IJAR, 2016,. All rights reserved.

Corresponding Author:- Nagla M.A. Mohammed.

Address:- Department of Medical Microbiology, Faculty of Medical Laboratory 


\section{Introduction:-}

Within the past two decades, Candida species have emerged as major human pathogens and are currently the fourth most common cause of nosocomial infection [1].

Nosocomial infections constitute a serious public health problem, and are among the major causes of morbidity and mortality in humans, leading to increased hospitalization time and, consequently, generating high costs for patient treatment [2]. Infections caused by Candida species have been increased dramatically worldwide due to the increase in immunocompromised patients [3].

Oropharyngeal candidiasis is a common infection in cancer patients and currently rank the most common human fungal disease [4].

Candida species are common members of the oral microflora and are generally regarded as being commensals. However, they are able to cause a range of opportunistic infections, referred to as candidiasis [5, 6].

The prevalence of diseases caused by Candida spp. has increased in recent years, mainly due to the increasing number of immunocompromised patients. Candida albicans is still the predominant species isolated, and it has the potential to infect virtually any tissue within the body. However, it is predominantly found on the oral and vaginal mucosa $[7,8]^{\circ}$

The prevalence of oral candidiasis in various countries varies among studies according to location, age of the patients, and the site sample, and has been reported to range from 20-75\% [9].

Over the years an incidence of $7.2-52 \%$ has been reported depending on treatment interventions and the type and stage of the malignancy [10].

Majority of oral infections are due to C. albicans but non-albicans strains such as C. glabrata and C. tropicalis have increasingly been implicated in causing disease [11].

The colonized Candida can invade the underlying mucosa and enter the blood stream leading onto disseminated disease with considerable morbidity and mortality if not treated promptly. Fluconazole is one of the first line drugs used for the treatment of oral candidiasis in cancer patients [12, 13]. Most studies place the crude mortality rate due to $C$. albicans infections at around $30 \%-40 \%,[14,15]$ but some have estimated this to be as high as $46 \%-75 \%$ [16].

A systematic review indicated that the weighed mean prevalence of clinical oral fungal infection during chemotherapy is $38 \%$ [17], and the most common forms of intraoral candidiasis reported in oncology patients are pseudomembranous and erythematous candidiasis[18, 19]. Pseudomembranous candidiasis can usually be diagnosed on the basis of its characteristic clinical appearance and may be accompanied by burning pain and taste changes. The appearance of erythematous candidiasis is relatively nonspecific, and laboratory testing may be needed to confirm the diagnosis. It may be accompanied by a burning sensation of the affected tissues [20].

Chemotherapeutic agents and therapeutic radiation disrupts the mucosal banner of the mouth, leading to severe oral mucositis, gingivitis, oral candidiasis, cellulitis and viral mucosal eruptions [21]. The oral mucositis or inflammation of the oral mucosa is painful and is characterized by erythema, edema, and mucosal shedding, which can lead to ulceration and secondary infection [22].

The irradiation-induced histological changes leading to oral mucositis, together with salivary quantitative and qualitative changes, have been reported to facilitate yeast growth [23].

Oral candidiasis presents as a removable white pseudomembrane or erythematous patch on the tongue, palate and labial commissures. It causes taste alterations, mucosal soreness and oral burning sensations. Heavy accumulations of candida may dislodge causing esophagitis, fungemia and pose aspiration risk to the patient [24]. 
The routine oral examination of cancer patients has revealed a greater incidence of Candida infections than that in most types of patients. Almost all surveys on fungal infections in cancer patients come from USA, Europe, and other developed countries, and little is known about this problem in developing countries, [1] particularly Sudan. For the first time we report on occurrence rate of oral Candidiasis among cancer patients at Isotope and Radiation center Khartoum.

\section{Materials and Methods:-}

It was a cross-sectional, case control study conducted in a period of 2015 to 2016 . The study involved 100 cancer patients (Out-patients ) as case study and 68 cancer patients (inpatients) as control groups, both group were under treatment of chemotherapy and/or radiotherapy in Radiation and Isotopes Centre Khartoum. Patients on antifungal therapy for past two weeks were excluded from the study. Both groups with a mean age of 48 years old, the patients were explained and informed consent was obtained from the patients. The demographic data, origin, type of cancer and treatment were considered in this study.

A total of 100 samples from cases and 68 from in-patients controls were included in the study. An examination of the oral cavity of the patients was performed and a sample from tongue, buccal mucosa and labial sulcus was taken with a sterile pre-moistened swab.

All samples were processed for yeast isolation in Microbiology laboratory following collection.

Oral Candida colonization was defined as presence of yeasts in the oral cavity irrespective of signs and symptoms. Oral candidiasis was defined as presence of Candida spp. in the oral cavity together with signs and symptoms of oral candidiasis like inflammation/mucositis and/or presence of white plaques confirmed microbiologically by the presence of yeasts and/or hyphae or pseudohyphae on potassium hydroxide-treated smears of oral swabs [25].

For all patients, the clinical diagnosis was confirmed microscopically by the presence of yeasts and hyphae or pseudohyphae on $10 \%$ potassium hydroxide $(\mathrm{KOH})$ preparation of oral swabs. Swabs were streaked onto Sabouraud's dextrose agar (SDA) to which chloramphenicol $(0.05 \mathrm{~g} / \mathrm{l})$ was added., which is the most useful and popular primary culture media [26]. Then the Plates were incubated at $37^{\circ} \mathrm{C}$ for $24-48$ hours, and Candida colonies appeared as cream coloured smooth or rough, shiny or dull and convex.

According to classification of oral candidoses [27], identification of Candida species was made using direct microscopy of the Gram stained smears that show characteristic rounded, or oval budding cells of yeast blastospores (yeast form) with or without the hyphal phase, which can be distinguished readily from bacteria by their greater size (3-6 $\mu \mathrm{m})$, budding, oval shape and pseudohyphae,.Identification of Candida species from growth in SDA media was done by germ tube test which it was perform to identify C.albicans, and to differentiate C.albicans from non albicans groups. Lightly touched single yeast colonies with sterile wire loop from the culture plate was inoculated in fresh human pooled serum and incubated at $37^{\circ} \mathrm{C}$ for $2-3$ hours. The wet mount preparation showed germ tube which is a hyphal projection, as mentioned in [28].

\section{Statistical analysis:-}

Data analyzed using Spss 21 (Statistical package for social sciences) with reference p-value (.05), P-value $\leq .05$ conceder as significant result. Frequencies and percent obtained in frequency tables, chi-square testfor goodness of fitused to test these frequencies. The relations between variables tested using cross tables and chi-square (Fisher exact)test for independence.

\section{Ethical consideration:-}

An approval was taken from the University, Faculty and Department of Medical microbiology management.

Consent was taken from Ministry of health, hospital and participants before taking samples.-

\section{Results:-}

The subject (168) involved in this study were cancer patients with chemotherapy and/or radiotherapy treatment, they represented (100) outpatients and (68) in-patients control group. The oral swab specimens were collected from 168 cancer patients and examined by cultural techniques. Candida species were isolated from $69(41.1 \%)$ patients while $99(58.9 \%)$ patients showed no growth. The culture result among the out-patients and control group as in figure (1). 


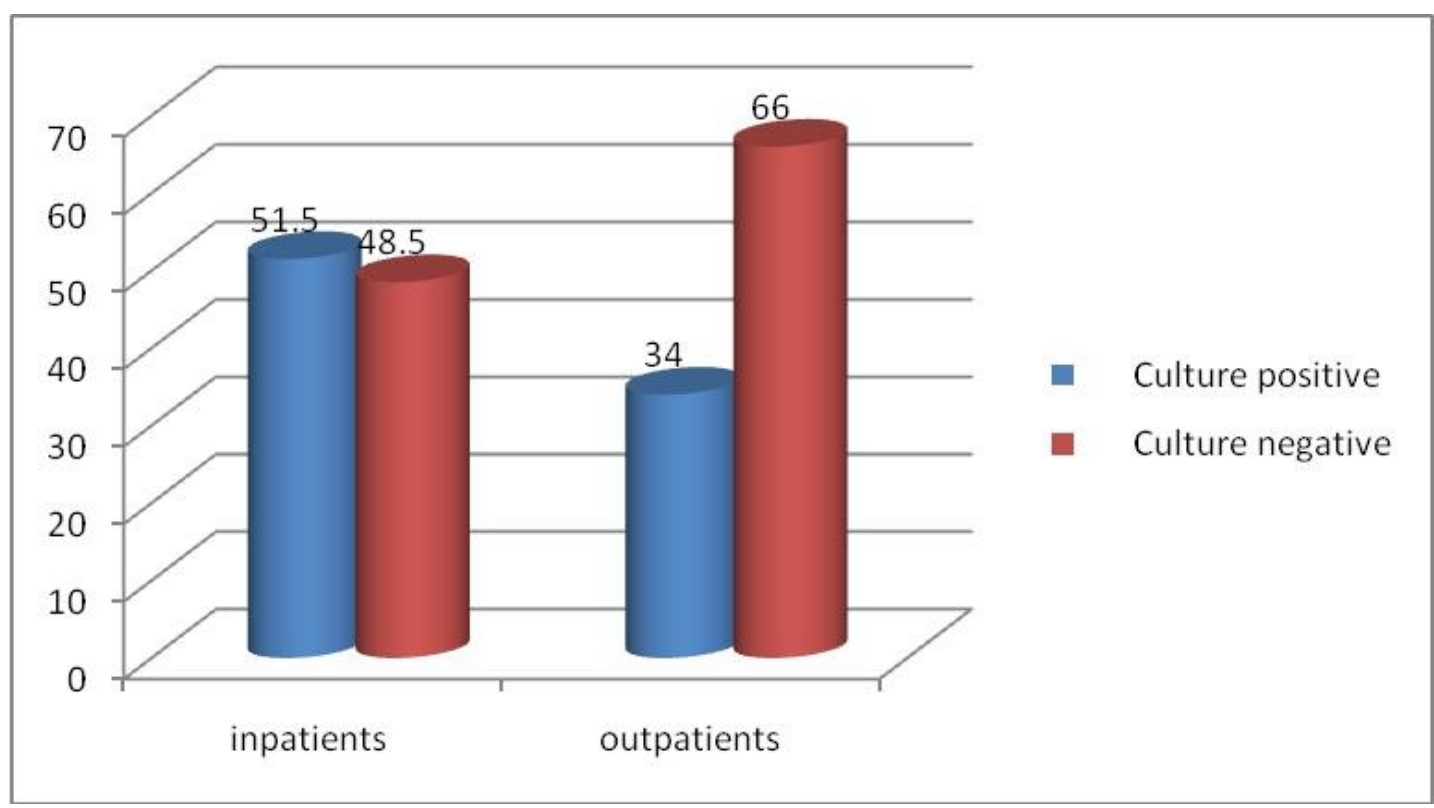

Figure 1:- Culture result according to the out-patients and in-patients control group.

The colonized Candida can invade the underlying mucosa and enter the blood stream leading onto disseminated disease. For all cancer patients the prevalence of oral candidiasis was 23(33.3) while the prevalence of oral colonization was (66.7), and significantly the infection was more common among inpatients group than outpatients. ( p value <0.05) (Table 1 ).

Table 1:- Frequency of oral infection and colonization

\begin{tabular}{|l|l|l|lc|}
\hline & Symptoms Infection) & No symptoms (Colonization) & \multicolumn{2}{|l|}{ Total } \\
\hline & Positive No \% & Positive No \% & No & \% \\
\hline Out-patients & $3(8.8)$ & $31(91.2)$ & 33 & 100 \\
\hline In-patients & $20(57.1)$ & $15(42.9)$ & 35 & 100 \\
\hline Total & $23(33.3)$ & $46(66.7)$ & 69 & 100 \\
\hline
\end{tabular}

In the present study it was found that C.albicans was significantly $(\mathrm{P}-<0.05)$ representing the most common isolated organism among both groups. (Figure 2)

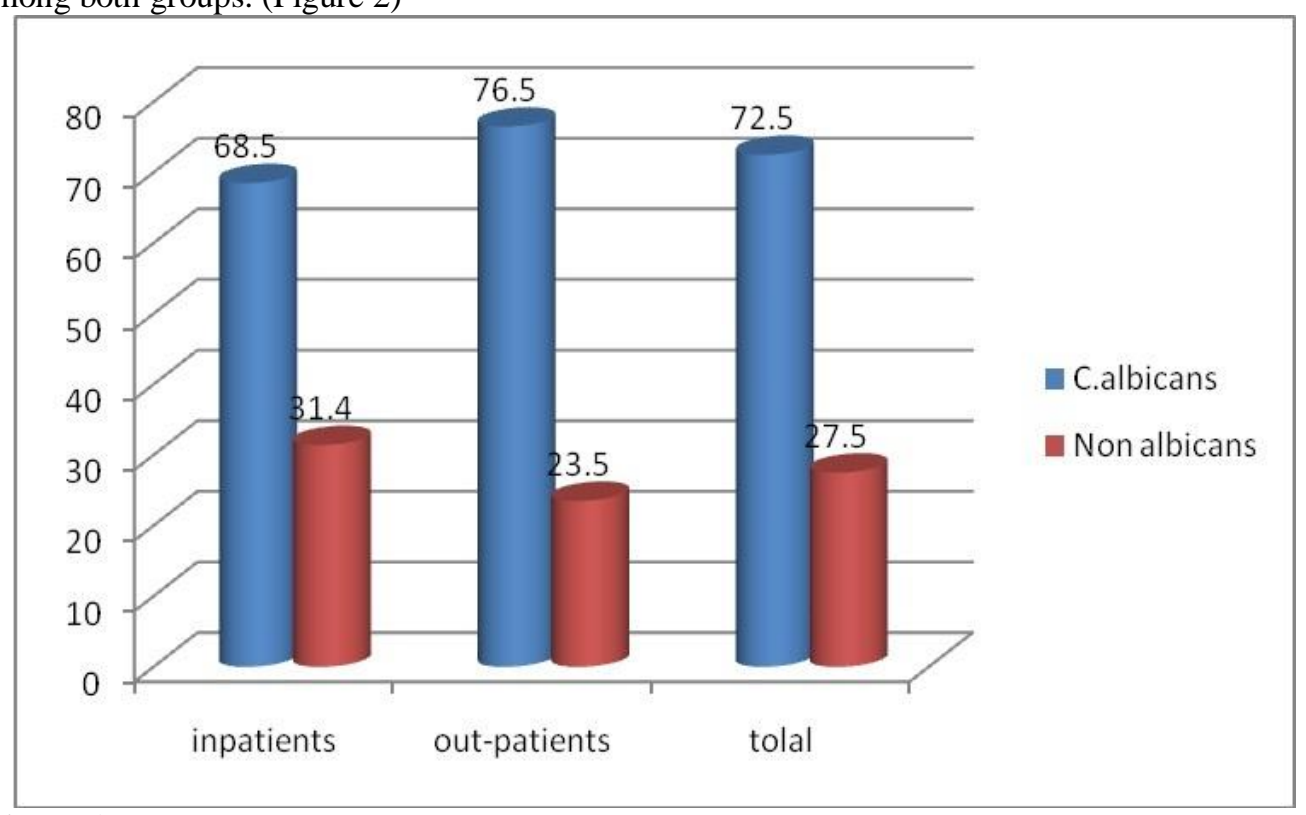

Figure 2:- Frequency of isolated Candida spp among out-patients and in-patients control group. 
Among the examined $76(45.3 \%)$ males and 92 (54.7\%) females, Candida species were found insignificantly more prevalent among females $42(45.5 \%)$ than males $27(35.5 \%)$. Similar in the inpatients group which represented $52.5 \%$ vs $44.4 \%$. whereas in the outpatient group showed $34.3 \%$ males and $33.3 \%$ females.

The age range of patients in study group was 15 to 85 years with mean age of 48.4 years; patients were classified into 4 groups according to the age group. (Table 2)

Table 2:- frequency of Candida isolates among cancer patients according to age group

\begin{tabular}{|c|c|c|c|c|c|}
\hline & & & \multicolumn{2}{|l|}{ Candida } & \multirow[t]{2}{*}{ Total } \\
\hline & & & Positive & Negative & \\
\hline \multirow[t]{8}{*}{ Age } & \multirow[t]{2}{*}{ 15-33 Year } & Count & 16 & 12 & 28 \\
\hline & & $\%$ within Candida & $23.2 \%$ & $12.1 \%$ & $16.7 \%$ \\
\hline & \multirow[t]{2}{*}{ 34-52 Year } & Count & 27 & 44 & 71 \\
\hline & & $\%$ within Candida & $39.1 \%$ & $44.4 \%$ & $42.2 \%$ \\
\hline & \multirow[t]{2}{*}{ 53-71 Year } & Count & 22 & 40 & 62 \\
\hline & & $\%$ within Candida & $31.9 \%$ & $40.4 \%$ & $36.9 \%$ \\
\hline & \multirow[t]{2}{*}{$<72$} & Count & 4 & 3 & 7 \\
\hline & & $\%$ within Candida & $5.8 \%$ & $3.0 \%$ & $4.2 \%$ \\
\hline \multirow{2}{*}{\multicolumn{2}{|c|}{ Total }} & Count & 69 & 99 & 168 \\
\hline & & $\%$ within Candida & $100.0 \%$ & $100.0 \%$ & $100.0 \%$ \\
\hline
\end{tabular}

P-value Chi square 0.187

Candida infection was more in patients treated with chemotherapy alone and least infection was shown in patients treated with radiotherapy (Table 3).

Table 3:- Distribution of isolated Candida spp according to type of cancer treatments

\begin{tabular}{|l|l|lc|}
\hline \multicolumn{2}{|l|}{ Treatment } & NO & $\%$ \\
\hline Categories & Chemotherapy \& Radiotherapy & 15 & 21.7 \\
\cline { 2 - 4 } & Chemotherapy & 47 & 68.1 \\
\cline { 2 - 4 } & Radiotherapy & 7 & 10.1 \\
\cline { 2 - 4 } & Total & 69 & 100.0 \\
\hline
\end{tabular}

P-value of chi-squared for goodness of fit $=.000$

The present study explained statistically significant distribution of oral candidiasis among cancer patients according to type of cancer (Figure 3 ).

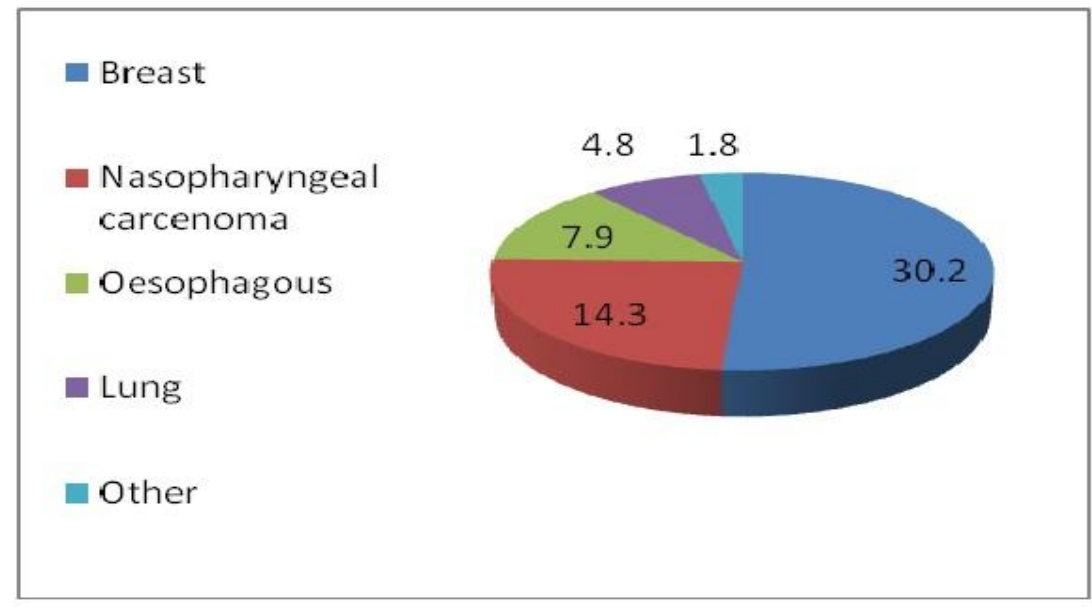

Figure 3:- Percentage of Candida spp according to the cancer sites in the patients tested. 
According to the environment and inherited genes of the Sudanese State, although all patients were treated in Isotope and Radiation Center are coming from different State. The high numbers of examined patients are from Khartoum state followed by Gezira State (Table 4). And according to the tribes more infection in Al-Gaalia tribe 6 out of $69(8.8 \%)$ followed by Zagaoa 4 out of $69(5.9 \%)$.

Table 4:- Frequency of oral Candidiasis among cancer patients according to origin

\begin{tabular}{|c|c|c|c|c|c|}
\hline \multirow[t]{2}{*}{ States } & & \multicolumn{2}{|c|}{ positive } & \multicolumn{2}{|c|}{ total } \\
\hline & & \multicolumn{2}{|c|}{ No $\%$} & \multicolumn{2}{|c|}{ No $\%$} \\
\hline \multirow[t]{12}{*}{ The first 12 prevalent States } & Khartoum & 7 & 10.3 & 2 & 12.0 \\
\hline & Gezira & 3 & 4.3 & \multicolumn{2}{|c|}{$\begin{array}{ll}18 & 10.8\end{array}$} \\
\hline & North sudan & 9 & 13.2 & 18 & 10.8 \\
\hline & South Dar-for & 9 & 13.2 & 16 & 9.6 \\
\hline & White Nile & 8 & 11.8 & 13 & 7.8 \\
\hline & Nortn kurdofan & 4 & 5.9 & 13 & 7.8 \\
\hline & South Kurdofan & 6 & 8.8 & 11 & 6.6 \\
\hline & North Dar-for & 2 & 2.8 & 9 & 5.4 \\
\hline & Al-gadarif & 1 & 1.4 & 8 & 4.8 \\
\hline & Sinar & 5 & 7.4 & 8 & 4.8 \\
\hline & Kasala & 4 & 5.9 & 6 & 3.6 \\
\hline & West Dar-for & 2 & 2.8 & 6 & 3.6 \\
\hline
\end{tabular}

P-value of chi-squared for goodness of fit $=.000$

\section{Discussion:-}

In the present study it was found that Candida species were isolated from $69(41.1 \%)$ patients while 99(58.9 \%) patients showed no growth. Also Lihua Xu, et al., [29] found that oral infection was prevalent in 46\% (391/850) of all cancer patients. Other studies have reported the incidence of oral candidiasis ranging from 7 to $52 \%$ in cancer patients on chemotherapy and/or radiotherapy [30].

The present study revealed the frequency of Candida isolates to be significantly more prevalent in in-patients than out-patients group (51.5\% vs. 34\%). Similar finding were obtainedby Hanan, et al. [31].

Regarding the infection and colonization it was found that among the total examined patients, the prevalence of oral candidiasis was 33.3 while $66.7 \%$ was colonization. Relatively similar result reprted by Mohd, et al. in (2014), [32] they found the total colonization to be prevalent in $50 \%$ and oral candidiasis in $30 \%$ of all cancer patients. Also Rajesh, et al [33] found that in a systematic review of oral fungal infections in patients receiving cancer therapy, the weighed prevalence of clinical oral infection (oral candidiasis) and oral colonization during treatment was $39.1 \%$ and $72.2 \%$, respectively.

In a study done by [31]. It was found that in-patients cancer group harboured Candida spp at significantly high levels than out patients. This study clearly demonstrated similar result that oral candidasis was significantly higher among in-patients $(42.9 \%)(\mathrm{P}$ value $<0.05)$ than out patients group $(8.8 \%)$, while colonization are more common in the out patients group Table (1).

Several previous works [31, 28, and 34] that studied the prevalence of oral Candida spp demonstrated that Candia albicans was the most prevalent organism. Similarly the present study revealed Candida albicans to be the most common organism both among out-patients and in-patients control group (76.5\% vs. 68.5\%), respectively. also Shaheen, et al, found that $C$. albicans to be the only species recovered from non hospitalized patients(100\%) while in hospitalize patients it was only $56 \%$.

Oral infection was insignificantly more common among females than males $(\mathrm{p}<0.05)$. This may be due to increase number of females than males in this study. This finding is in agreement with the study of Intisar, et.al [35] who studied a total of 6771 cases of cancer incidence, they found females cases as $53.8 \%$ and males (46.2\%).

The higher prevalence of oral candidiasis was found among the age group (34-52) year followed by the age group 53-72 years. This may be due to the fact that, the most cancer patients were occupaied in this group, as reported by 
study, ${ }^{[35]}$ that the higher incidence cases of cancer were recorded among Khartoum residents in 2009-2010 were between 25-54 years. Similar previous finding found $C$. albicans present in the oral cavities of patients belonging to age group of $40-60$ years than in any other age group [36].

Amongst the cases $(\mathrm{n}=168), 147(87.5 \%)$ had solid organ malignancy and $21(12.5 \%)$ patients with hematological malignancy. Breast cancer patients represented the higher group among different types of cancer in Sudan ${ }^{[36]}$ this agrees with the fact that this type of cancer is a worldwide distribution in different countries. It was found the high frequently of Candida spp. appeared in patients with breast cancer, which is in accordance to other investigation [37], this is in agreement with this study.

The current study showed significant increased percentage (63.9\%) of Candida isolates among chemotherapy treated patients as most of the cases 114 (67.9\%) under chemotherapy treatment only. It is well known that cancer and chemotherapy result in immunosuppression which gives opportunity for emergence of Candida infection. The outcome is the immune dysfunction and mucosal damage which promote yeast infections such as mucositis, xerostomia and candidiasis [38, 39]. It is well known that prolonged use of chemotherapy may lead to neutropenia, disruption of mucosal barrier and overall damage to cell mediated immunity which increases the risk of infection. [40].

Although the high number of cancer patients in the current study were represented at Khartoum State followed by Gezira State. Oral candidiasis was found more common among patients who are from North Sudan and South Darfor (13.2\%) equally. and among those who belong to Al-gaalia tribe (8.8\%) table (4). This may be due to either inherited genes or environmental factors, thus further studies must be carried out to enrich this field.

\section{Conclusion:-}

In the present study we demonstrate that $C$. albicans and other Non- C. albicans species are associated commonly with the oral cavity in immounocompromised patients. Oral colonization and infection by Candida spp. is a matter of concern especially among in-patients group as multiple risk factors contribute to such a scenario in this vulnerable group.

The incidence of this yeast varies depending on cancer type, sex, and age; type of cancer treatment, origin and tribe of patients.

The frequent occurrence of Candida species in oral cavity of immounocompromised patients indicates a need for effective management for the isolation and identification of this yeast prior to any treatment.

\section{Acknowledgements:-}

The authors like to thank each patient who graciously allowed us to take oral swab from him, despite suffering from the disease; also thanks are due to everyone one who helps us during this study.

\section{References:-}

1. Afraseyabi SH, Afkhamzadeh A, Sabori H, Verdi F, Khaksar N, Mosavei B, et al. Oral candidiasis amongst cancer patients at Oods hospitals in Sanandaj. Afr. J. Cln. Exper. Microbiol . 2011; 12(3): 129-132

2. Barchiesi F, Caggiano G, Falconi Di Francesco L, Montagna MT, Barbuti S, Scalise G. Outbreak of fungemia due to Candida parapsilosis in a pediatric oncology unit. Diagn Microbiol Infect Dis. 2004; 49: 269271.

3. Anaul Kabir M, Zulfiqar Ahmad. Candida infection and their prevention. ISRN Preventive Med. 2013; V 2013.

4. Akapan A, Morgan R. Oral Candidiasis: a review .postgard.Med.J. 2002; 78, 455-459.

5. Williams DW, Bartle KL, Potts AJ, Willson MJ, Fardym J, Lewism A. Strain persistence of invasive Candida albicans in chronic hyperplastic candidosis that underwent malignant change. 2001; Gerodontology. 18: 73-78.

6. Morace G, Borghie E. Fungal infections in ICU patients: epidemiology and the role of diagnostics. Minerva Anestesiol. 2010; 76: 950-956.

7. De Araujo Navas EA, Inocencio AC, Almeida JD, Back-Brito GN, Mota AJ, Jorge AO, et al. Oral distribution of Candida species and presence of oral lesions in Brazilian leprosy patients under multidrug therapy. J. Oral. Pathol. Med. 2009; 38: $764-767$. 
8. Maninder J, Usha A. Isolation, characterization and antifungal susceptibility pattern of Candida species causing oropharyngeal candidiasis in HIV positive patients. J. Commun. Dis. 2008; 40: 177-181.

9. Hana M, Khaled H, Ali Z, Mawieh H. Isolation and characterization of Candida spp. In Jordanian Patients: Prevalence, Pathogenic Determinants, and antifungal sensitivity. Jpn. J. Infect. Dis. 2004; 57: 279-284.

10. Jham BC, Franca EC, Oliveira RR, Santos VR, Kowalski LP, da Silva Freire AR. Candida oral colonization and infection in Brazilian patients undergoing head neck radiotherapy: a pilot study. Oral Surg Oral Med Oral Pathol Oral Radiol Endod. 2007; 103: 335-58

11. Bagg J, Sweeney MP, Lewis MAO, et al. High prevalence of non-albicans yeast and detection of anti-fungal resistance in the oral flora of patients with advanced cancer. Palliat Med. 2003; 17: 477-81

12. Lalla RV, Latortue MC, Hong CH, Ariyawardana A, D'Amato-Palumbo S, Fischer DJ. and et al. A systematic review of oral fungal infections in patients receiving cancer therapy. Support Care in Cancer. 2010; 18 (8) 985-992,

13. Shokohi ZT, Bandalizadeh MT, Hedayati, Mayahi S. In vitro antifungal susceptibility of Candida species isolated from oropharyngeal lesions of patients with cancer to some antifungal agents. Jundishap J. of Microbiol. 2011; 4(1) S19-S26.

14. Pfaller M, Neofytos D, Diekema D, Azie N, Meier-Kriesche HU, Quan SP, Horn D. Epidemiology and outcomes of candidemia in 3648 patients: Data from the Prospective Antifungal Therapy (PATH Alliance(R)) registry, 2004-2008. Diagn. Microbiol. Infect. Dis. 2012; 74: 323-331.

15. Das I, Nightingale P, Patel M, Jumaa P. Epidemiology, clinical characteristics, and outcome of candidemia: Experience in a tertiary referral center in the UK. Int. J. Infect. Dis. 2011; 15: e759-e763.

16. Brown GD, Denning DW, Gow NA, Levitz SM, Netea MG, White TC. Hidden killers: Human fungal infections. Sci. Transl. Med. 2012; 4: 165rv113.

17. Underhill DM, Iliev ID. The mycobiota: Interactions between commensal fungi and the host immune system. Nat. Rev. Immunol. 2014; 14: 405-416.

18. Nucci M, Anaissie E. Revisiting the source of candidemia: Skin or gut? Clin. Infect. Dis. 2001; 33: 1959-1967.

19. Miranda LN, van der Heijden IM, Costa SF, Sousa AP, Sienra RA, Gobara S, Santos CR, Lobo R.D, Pessoa VP, Levin AS. Candida colonisation as a source for candidaemia. J. Hosp. Infect. 2009; 72: 9-16.

20. Epstein JB, Vickars L, Spinelli J, Reece D. Efficacy of chlorhexidine and nystatin rinses in prevention of oral complications in leukemia and bone marrow transplantation. Oral Surg Oral Med Oral Pathol. 1992; 73(6): 6829.

21. Lalla RV, Latortue MC, Hong CH, Ariyawardana A, Amato D, Palumbo S. et. al. A systematic review of oral fungal infections in patients receiving cancer therapy. Support Care Cancer. 2010 18(8):985-992.

22. Raber-Durlacher JE, Weijl NI, Abu Saris M, de Koning B, Zwinderman, AH, Osanto S. Oral mucositis in patients treated with chemotherapy for solid tumors: a retrospective analysis of 150 cases. Suppor Care Cancer. 2000; 8:366-371.

23. Silverman SJ, Luangjarmekorn L, Greenspan D, Occurrence of oral Candida in irradiated head and neck cancer patients. J Oral Med. 1984; 39:194-196.

24. Epstein JB, Gorsky M, Caldwell J. Fluconazole mouthrinses for oral candidiasis in postirradiation, transplant, and other patients. Oral Surg Oral Med Oral Pathol Oral Radiol Endod. 2002; 93:671-675.

25. Rautemaa R, Rusanen P, Richardson M, Jukka H. Meurman Optimal sampling site for mucosal candidosis in oral cancer patients is the labial sulcus. 2006; $\mathbf{5 5}: 1447-51$

26. Shubhangi K, Alka D, Neha U, Mishra KR, Shalini G, Rohit M. Diagnostic technigue of oral candidosis: Areview. IOSR-JDMS. 2013; 9 (1) 63-67

27. Samaranayake LP, Yaacob H. Classification of oral Candidoses: In Oral candidoses. London:Butterworth. 1990; Pg No 124-132

28. Lsmet N, Shirin T, Rehana RK, Ali SM, Ahmed AS. Species identification of Candida isolated from clinical specimens in tertiary care hospital. BSMMU J. 2016; 9(1) 20-25.

29. Lihua $\mathrm{Xu}$, Hualin $\mathrm{Z}$, Jinsong $\mathrm{L}$, Xiaowei C. Investigation of the oral infections and manifestations seen in patients with advanced cancer. Pak J Med Sci. 2013; 29(5):1112- 1115.

30. Lone MS, Bashir G, Bali N. Oral Candida colonization and infection in cancer patients and their antifungal susceptibility in a tertiary care hospital. Inter. J. of Advan Resear. 2014; 2(5): 541-550.

31. Hanan M, AL-Abied KH, Abu-Elteen AZ. ,Elkarmi, and Mawieh,A.H. Isolation and characterization of Candida species in Jordanian cancer patients: Prevalence, pathogenic determinants and antifungal sensitivity. JPN.J. Infet. Dis. 2004; 57: 279- 284.

32. Mohd SL, Gulnaz BN, Syed S, Shiekh A, Humaira BJ. Oral Candida colonization and infection in cancer patients and antifungal susceptibility in a tertiary care hospital. Inter. $\mathrm{J}$ of advan resear. 2014; 2(5): 541-550. 
33. Rajesh V, Lalla MC, Latortue CH, Hong AA, Sandra DA, Dena JF, et al. Asystematic review of oral fungal infections in patients receiving cancer therapy. Support care cancer J. 2010; 18(8): $985-992$

34. Mustafa AA, Nasir AA, Bashar SA. Isolation and identification of Candida species from the oral cavity of cancer patients undergoing chemotherapy in Basrah. Irag. J. of Biol, Agricul and Healthca. 2016; 6(18).

35. Intisar ES, Hsin-Yi W, Kamal HM, Sulma IM. Cancer incidence in Khartoum, Sudan: first results from the Cancer Registry, 2009-2010. Cancer Med. 2014; 3(4): 1075-1084.

36. Dixit S, Goswami S, Dive A. Determination, distribution \& phenotypic differentiation of Candida : Study in oral precancer and oral cancer. India J. of Dent resear and review. 2012.

37. DiNubile M, Hille D, Sable C, Kartsonis N. Invasive candidiasis in cancer patients: observations from a randomized clinical trial. J. of Infect. 2008; 50(5): 443-449.

38. Singh S, Fatima Z, Hameed S. Predisposing factors endorsing Candida infections. Le infezioni in Medicina. 2015; 3: 211-223.

39. Caira M, Candoni A, Verga L, Busca A, Delia M, Nosari A, et al. Pre-chemotherapy risk factors for invasive fungal diseases: Prospective analysis of 1,192 patients with newly diagnosed Acute Myeloid Leukemia (SEIFEM 2010-A Multicenter study). Haematologica. 2015; 100: 284-292.

40. Kang J, He Y, Hetzel D, Jiang HQ, Jun MK, Jun MS, et. al. A candid assessment of the link between oral Candida containing biofilms and oral cancer. Advan Microbiol. 2016; 6: 115-123. 